\title{
FINITE ELEMENT ANALYSIS OF SINGLE WHEAT MECHANICAL RESPONSE TO WIND AND RAIN LOADS
}

\section{Li Liang, Yuming Guo*}

College of Engineering \$ Technology, Shanxi Agricultural University, Taigu, Shanxi Province, P. R. China 030801

* Corresponding author, Address: College of Engineering \$ Technology, Shanxi Agricultural University, Taigu,030801, Shanxi Province, P. R. China, Tel: +86-354-6288906, Fax: +86354-6288906,Email: guoyuming99@sina.com

Abstract: One variety of wheat in the breeding process was chosen to determine the wheat morphological traits and biomechanical properties. ANSYS was used to build the mechanical model of wheat to wind load and the dynamic response of wheat to wind load was simulated. The maximum Von Mises stress is obtained by the powerful calculation function of ANSYS. And the changing stress and displacement of each node and finite element in the process of simulation can be output through displacement nephogram and stress nephogram. The load support capability can be evaluated and to predict the wheat lodging. It is concluded that computer simulation technology has unique advantages such as convenient and efficient in simulating mechanical response of wheat stalk under wind and rain load. Especially it is possible to apply various load types on model and the deformation process can be observed simultaneously.

Keywords: finite element analysis, mechanical response, wheat stalk, wind and rain loads

\section{INTRODUCTION}

Crop lodging is one of the most important factors affecting wheat yield. Many researchers have studied the wheat lodging resistance for years. (1) Building mechanical models of crops are a popular method to evaluate the wheat lodging resistance capability by analyzing the mechanical response of

Please use the following format when citing this chapter:

Liang, L. and Guo, Y., 2009, in IFIP International Federation for Information Processing, Volume 294, Computer and Computing Technologies in Agriculture II, Volume 2, eds. D. Li, Z. Chunjiang, (Boston: Springer), pp. 841-846. 
wheat stalk under wind. Some theoretical models were introduced to analyze the natural frequencies for cereals and trees under wind (C.J. Baker, 1995, S. E. T. Saunderson, et al, 1999, Yuan Zhihua, et al. 2002). However, most of these models are calculated by pure theory and the calculating process is extremely complicated. Sometimes, only the numerical solution is obtained by software for numerical mathematics (Hanns-Christop Spatz, Olga Seck, 2002). (2) Field tests of wheat were carried out in a portable wind tunnel (M. Sterling, et al., 2003), which could simulate the mechanical response of wheat close to the natural situation, but the testing and control system of wind tunnel is difficult to design and very costly.

With the development and application of computer technology in agriculture, more agricultural problems have been solved by computer. For example, in the field of simulating crop growth, many results are obtained. A peach crop production computer simulation model has been built to predict the fruits growth (T. M. DeJong, et al. 1990). Two models were utilized to simulate the effects of $\mathrm{CO}_{2}$ and ozone on growth and developmental processes of spring wheat in response to climatic conditions (F. Ewert, et al. 1999). Methods for estimating potential evaporation and potential transpiration among crops are presented to help predict the soil moisture (Huang Guanhua, 1995).

A mechanical model of wheat under wind and rain loads built by ANSYS software is introduced in this paper. And mechanical responses of wheat are simulated. This method is convenient for applying different type of loads on model. The change of stress and displacement during loading can be shown clearly with stress and displacement nephograms. Besides, the maximum Von Mises stress is calculated simultaneously to predict the dangerous position.

\section{FINITE ELEMENT MODEL OF SINGLE WHEAT}

\subsection{Element type and material attributes}

In the process of building wheat finite element model, Beam188 (defined in ANSYS) shown in Fig. 1 is chosen to be the element type.



Fig. 1. Beam188 Geometry 
It is suitable for analyzing slender to moderately stubby/thick beam structure. It is based on Timoshenko beam theory, and also considered shear deformation effects. A cross-section associated with this element type can be a built-up section referencing more than one material and the cross-section characteristics of beam can be shown clearly.

Due to different material of each wheat internode, morphological traits and biomechanical properties of wheat variety in the breeding process (named ShanNong040121-135) were tested during the wheat mature stage at June16th, 2007. Mean of the tested indexes are listed in Table1.

Table 1. Mean of wheat morphological traits and biomechanical properties

\begin{tabular}{cccccccc}
\hline $\begin{array}{c}\text { Internode } \\
\text { number }\end{array}$ & $\begin{array}{c}\text { Internode } \\
\text { Distance } \\
(\mathrm{mm})\end{array}$ & $\begin{array}{c}\text { diameter } \\
(\mathrm{mm})\end{array}$ & $\begin{array}{c}\text { wall } \\
\text { thickness } \\
(\mathrm{mm})\end{array}$ & $\begin{array}{c}\text { Ear } \\
\text { weight } \\
(\mathrm{g})\end{array}$ & $\begin{array}{c}\text { Young's } \\
\text { modulus } \\
(\mathrm{MPa})\end{array}$ & $\begin{array}{c}\text { Bending } \\
\text { strength } \\
(\mathrm{MPa})\end{array}$ & $\begin{array}{c}\text { Bending } \\
\text { rigidity } \\
\left(\mathrm{Nmm}^{2}\right)\end{array}$ \\
\hline 1 & 78.49 & 3.63 & 0.83 & & 2168.62 & 27.18 & 16203.73 \\
2 & 118.69 & 3.60 & 0.54 & & 2228.98 & 19.85 & 14601.44 \\
3 & 139.80 & 3.68 & 0.45 & 3.89 & 1429.63 & 15.32 & 8925.47 \\
4 & 176.76 & 3.58 & 0.37 & & 1458.55 & 13.84 & 7256.45 \\
5 & 284.86 & 2.96 & 0.43 & & 1973.65 & 13.39 & 5464.96 \\
\hline
\end{tabular}

Biomaterials including wheat stalk have more complicated properties than other engineering materials. It is strictly a viscoelastoplastic material. However, it is difficult to test the related index so that the stalk material in this paper is supposed as linear isotropic elasticity. The parameters of material properties are defined according to Table 1 from the bottom to the top of the stalk. Poisson's ratio is taking as 0.413 determined by our test.

\subsection{Finite element model}

Wheat stalk is simplified as cantilever beam of variable rigidity with an apical load. It is negligible mass of the stalk (Hanns-Christof Spatz and Olga Speck, 2002). The beam cross-section is defined as circular hollow section and the value is determined according to table1. Wind load is applied as pressure on the beam which is calculated by the formula as follows:

$$
\omega=\frac{v^{2}}{1600}
$$

Where: $U$ is wind speed.

The apical load is ear weight applied on the stalk as concentrated force.

Large displacement static is chosen as the analysis type. When rain and wind loads are applied together, rain load is simplified as concentrated force applied on the top of stalk. The finite element model is shown in Fig. 2. 


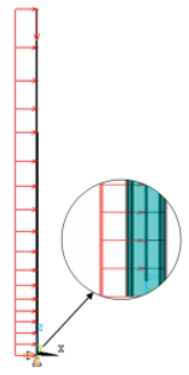

Fig.2. Stalk mechanical model

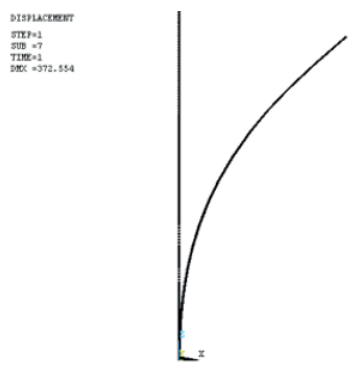

Fig. 3. Stalk deformed shape at wind speed of $3.4 \mathrm{~m} / \mathrm{s}$

\section{RESULTS AND ANALYSIS}

Various displacements and stresses for single stalk under different loads were obtained by changing load type and size. Fig. 3 shows the deformed shape of wheat stalk under wind load. Meanwhile, the software can calculate the value of displacement and stress for each node and finite element. The results are presented as displacement and stress nephogram. It indicates that the maximum Von Mises stress of wheat stalk under wind load occurs at the second internode.

(1) Wind load acts alone. At wind speed of $3.4 \mathrm{~m} / \mathrm{s}$, the maximum displacement down the wind direction is $353.634 \mathrm{~mm}$, the vertical maximum displacement is $119.467 \mathrm{~mm}$ and the maximum von mises stress is $4.52 \mathrm{MPa}$. When wind speed reaches to $19.3 \mathrm{~m} / \mathrm{s}$, the top of wheat stalk is close to ground and the maximum Von Mises stress is $16.996 \mathrm{MPa}$, which is lower than the bending strength of wheat stalk. Therefore, it will be returned to its original position. Von Mises stress nephograms for single wheat under above wind speeds are shown in Fig. 4.

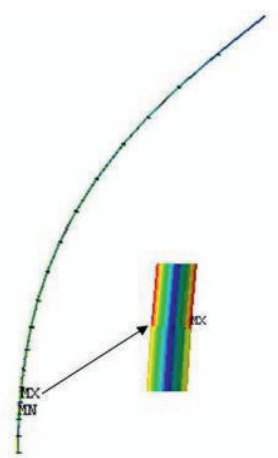

A

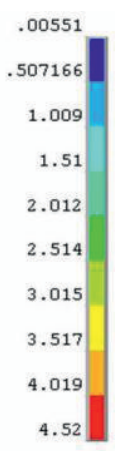

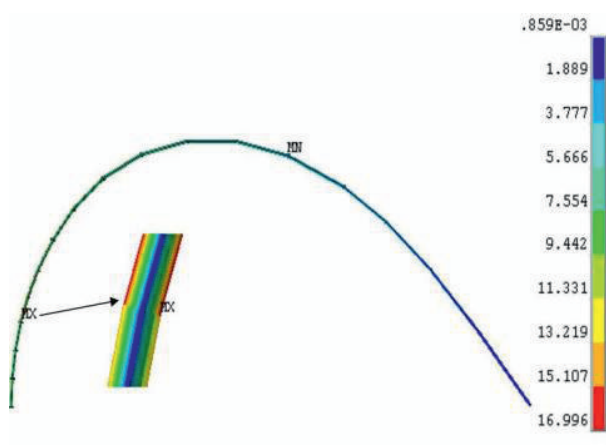

B

Fig. 4: Stalk nodal Von Mises stress at wind speed of $3.4 \mathrm{~m} / \mathrm{s}$ (A) and $19.3 \mathrm{~m} / \mathrm{s}$ (B) (MPa) 
(2) Both wind and rain load are considered. Assume that ear weight adds rain load of $0.01 \mathrm{~N}$. The maximum displacement in horizontal direction is $525.412 \mathrm{~mm}$, and in vertical direction is $331.093 \mathrm{~mm}$ when wind speed is 3.4 $\mathrm{m} / \mathrm{s}$. The maximum Von Mises stress is $7.945 \mathrm{MPa}$ as shown in Fig. 5 (A). The maximum Von Mises stress of wheat increases $75.8 \%$ compared to the situation when wind load acts alone. The vertical displacement of wheat stalk reaches the largest point at wind speed of $17.8 \mathrm{~m} / \mathrm{s}$, and the Von Mises stress is $16.886 \mathrm{MPa}$ as shown in Fig. 5 (B). Because of rainfall, the field becomes wet and soft. At that moment, both stem and root lodging might be occurred.

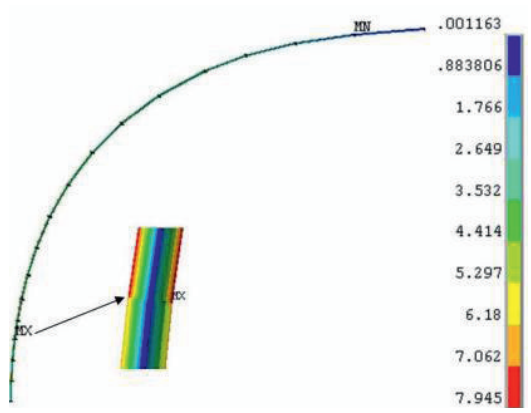

A

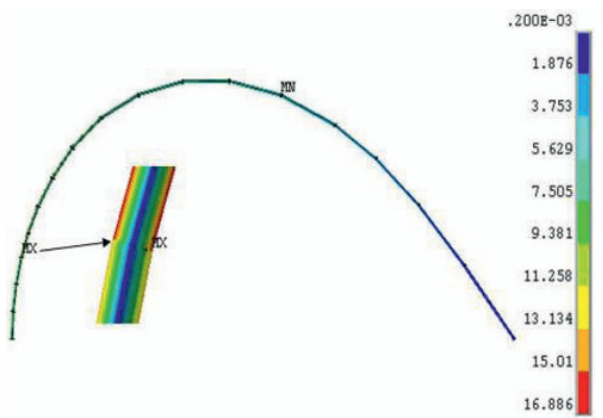

B

Fig. 5: Stalk von mises stress $(\mathrm{MPa})$ nephogram considered rain weight at wind speed of $3.4 \mathrm{~m} / \mathrm{s}(\mathrm{A})$ and $17.8 \mathrm{~m} / \mathrm{s}(\mathrm{B})$

\section{DISCUSSION}

Displacement and stress responses for single wheat under different load are simulated by ANSYS software. It is concluded that

(1) When wind load acts on wheat alone, lodging is difficult to occur. If both wind and rain load are considered simultaneously, the vertical displacement of wheat stalk is already reaches the utmost at wind speed of $17.8 \mathrm{~m} / \mathrm{s}$ with ear added $1 \mathrm{~g}$ rainfall amount. Lodging is easier to happen.

(2) At the same wind speed of $3.4 \mathrm{~m} / \mathrm{s}$, the vertical displacement of wheat stalk increases $177.1 \%$ and Von Mises stress increased $75.8 \%$ considered rain load, compared to the wind load acts alone.

(3) Related analysis above indicates that computer simulation method has unique advantages on analyzing the mechanical response of wheat stalk under various wind and rain load. It is convenient and efficient to help predict the wheat lodging. And the powerful calculation function is useful to evaluate the load support capability and present the changeable trend of displacement and stress. Therefore, fine results can be obtained in deformation analysis. However, in the process of building finite element 
model, the material properties of wheat stalk is assumed as linear isotropic viscoplastoelastic, which is an ideal status. The applying types of wind and rain loads still need to do further study. These problems will be studied accompanied by verifying the model with experiment and improving it.

\section{ACKNOWLEDGEMENT}

Funding for this research is provided by Doctoral Fund of Ministry of Education of P. R. China. The authors would like to thank the college of agriculture in Shanxi Agricultural University (P. R. China) to provide wheat for testing.

\section{REFERENCES}

C. J. Baker. The development of a theoretical model for the windthrow of plants. J. theor. Biol. 1995, 175: 355-372

F. Ewert, M. Oijen, van. J. R. Porter, Simulation of growth and development processes of spring wheat in response to $\mathrm{CO} 2$ and ozone for different sites and years in Europe using mechanistic crop simulation models. Journal of the European Society for Agronomy, 1999, 10(3-4): 231-247

Hanns-Christof Spatz, Olga Speck. Oscillation Frequencies of Tapered Plant Stems. American Journal of Botany, 2002, 89(1): 1-11

Huang Guanhua, Shen Rongkai, Zhang Yufang, et al. Simulating Evaporation and Transpiration and Forecasting Soil Moisture Regime under Conditions of Crop Growth, Journal of Wuhan University of hydraulic and electric engineering, 1995, 28(5):481-487 (in Chinese)

M. Sterling, C.J. Baker, P.M. Berry, A. Wade. An experimental investigation of the lodging of wheat, Agricultural and Forest Meteorology, 2003, 119(3-4):149-145

S. E. T. Saunderson, A. H. England, C. J. Baker. A Dynamic Model of the Behavior of Sitka Spruce in High Winds, J. theor. Biol. 1999, 200(3): 245-259

T. M. DeJong, R. S. Johnson, S. P. Castagnoli, Computer simulation of the carbohydrate economy of peach crop growth. Acta horticulturae, 1990, (276): 97-104

Yuan Zhihua, Li Yundong, Chen Heshun. Dynamic model and vibration analysis of wheat or sort, Hennan Science, 2002, 20 (1):11-13. (in Chinese) 